\title{
Shuttling among futures in the symbolic alchemy of the Mysterium coniunctionis
}

\author{
Kirk W. Junker * \\ Cross-Border Programme in Science Communication, Dublin City University and The Queen's \\ University of Belfast, 39 Abbey Street, Armagh BT61 7EB, Northern Ireland, UK
}

\begin{abstract}
Contrary to the notion that the human mind has some sort of tendency toward the abstract processes of classifying, analysing and synthesising, this paper suggests that these processes are historically and socially constructed. Because these processes (in particular, synthesising) are brought about to serve specific purposes and agendas, we need to re-examine them periodically to see if they still serve our needs. In the past, synthesis had an important function as a symbol, among alchemists, for example. We have all but forgotten that symbolic functioning and treat it now only in its material manifestations. Having done so, we use the material sense to explain the symbolic sense. In that way, synthesis may no longer be a helpful way to look at our abstract processes. Insofar as the needs of the future may be different than the needs of the past or present, it may indeed be time to abandon ideas of abstract synthesis. The author suggests that in its place, we consider the notion of 'shuttling'. Shuttling allows us to adopt different positions, and even contradictory positions within our individual thinking, without feeling the need to immediately characterise the contradiction as 'wrong'. And insofar as we may have multiple present positions, shuttling opens up the possibility for multiple future positions as well. (C) 2000 Elsevier Science Ltd. All rights reserved.
\end{abstract}

\section{Why shuttle and not synthesise?}

I find that one of the most persuasive and important agendas for future studies is the project of enabling the existence of multiple futures. In advocating for this project of multiple futures, however, we often focus our energies only on the stuff of what each of those futures might be. Thus the project takes on a mode of defining and describing the substance of each of those futures. It is as though by establishing the

* Tel.: +44-1861-510678; fax: +44-1861-510679.

E-mail address: k.junker@qub.ac.uk (K.W. Junker) 
mere existence of multiple futures we guarantee the conceptual independence and autonomy of each of those futures. There are problems with this approach, however. No socio-political concept has ever before enjoyed that sense of independence and autonomy, so why should the concept of a future be able to do so? It cannot. A future will affect and be affected by other futures, even when multiple ones may co-exist. That being the case, we need to focus upon not just what the futures themselves are, as ontic entities, but we must also focus upon their relationships to each other, and what the dynamic principles are that move us from one to the other.

My concern here is not the stuff of futures, but the relationships among that stuff, whatever we determine the stuff to be. I am concerned that the relationships recognise that futures, like pasts and even presents, are abstract concepts belonging to a world of symbols. It is these concerns that cause me to argue for a relationship among futures characterised as shuttling rather than as synthesis. One of the maxims of postmodernist discourse is that the individual self has become 'fragmented', 'fractured' or 'dis-integrated.' At issue are such questions as: Do we say this because the status of the self has changed or because it has always been in such a state of fragmentation and we have just now discovered that fact? If we accept this maxim, what might it mean for future studies? What are the relationships among the various selves? How do we move from one self to the other; how do we regard the motion that is that movement? It is in addressing these questions that I arrive at what I call 'shuttling.'

Shuttling is usually defined as moving to and fro over short distances. The toand-fro nature does not suggest that the places moved to or from have a centre or main point. But there are more than two points in multiple futures. If we add more dimensions, so that we say we are shuttling among, rather than shuttling between, we begin to see the idea of moving among a network of points spread over distances, still without a centre or main point, as bees do when they visit from blossom to blossom. In the abstract, this may sound like a tenable procedure for making choices and decisions among various possible ideas; among various possible future paths. But if we examine it a bit closer, we find that such an approach has in fact not been the case- 'synthesising' has been the case; a process of moving from point to point in an effort to make them all converge and direct the arrow of progress toward one path into the future.

By comparison, what do we mean by 'synthesis'? When I did my library search regarding 'synthesis', I found more than 400 book titles containing the word, but fewer than ten used the word in a way different than that of chemistry. In many cases, the word was a synonym for 'artificial'. And as to journals, three had 'synthesis' in the title, and all were in the field of chemistry. What can we make of this? Well if the overwhelming use of the word lies in the natural sciences, we might want to look precisely to the sciences, namely chemistry, to study the use of the word. I asked a colleague who is a university research chemist how he would define it, and he went to his bookshelf in the laboratory and gave me a definition from his chemist's dictionary: 'synthetic' means 'Describing a substance that has been made artificially; i.e. one does not come from a natural source.' And 'synthesis' means: 'The formation of chemical compounds from more simple compounds' [1]. As between the symbolic 
notions of shuttling and synthesis, it is synthesis that denies the potential of multiple futures while affirming its oath to progress.

In my little desktop dictionary the entry 'synthesis' falls between the entries 'syntax' and 'syphilis.' Playfully, I can find some meaning in this location of the entry in the dictionary. To me, the notion of synthesis lies somewhere between the positive notion of bringing things together to produce order, the way syntax does, and the negative aspects of bringing something together, the way in which 'syphilis' is transmitted. In other words, the meaning of synthesis lies between a sense of order and a disease. While still toying with definitions, we know the artificial sense of 'synthetic' when we examine our clothing and shoes-'natural or synthetic fibres?' we ask. If we then think about how we move from idea to idea, do we call the grouping of ideas natural or synthetic? In this light, all of a sudden synthesis may not look to be so positive. By simply changing the suffix to indicate an adjective (synthetic) rather than a noun (synthesis) or a verb (synthesise), the tone that we hear around the word changes considerably; and in large part, announcing it as an adjective sounds negative (except perhaps to the chemist).

Finally, in comparing shuttling to synthesising, one might also ask what my concept of shuttling would mean for progress? At first glance, synthesis may seem to offer an advantage over shuttling on this issue. But if one begins to practise a respect for alternatives by separating notions of progress into qualitative and quantitative, and focusing on the qualitative, shuttling will demonstrate its advantages. The more common notion of progress is the quantitative one, whereby progress means an accumulation-more facts, more things, more experiences-whatever the phenomenon may be. This is true in areas where we say that knowledge builds upon preceding knowledge, as when the knowers claim to have seen so far because they have stood on the shoulders of giants. This in turn has grave consequences for qualitative notions of progress. Jacob Bronowski has effectively distinguished these two different notions of progress in one aphoristic observation-the average physics student today knows more facts (of physics) than Newton himself... but has less knowledge [2]. In other words, accumulating a greater quantity of knowledge does not mean obtaining a better quality of knowledge.

\section{Aristotle and the principle of non-contradiction: how the West was one}

My comments are borne of, and directed toward, the West. I say this for two reasons. First, insofar as there are likely to be examples in Eastern thought that can provide patterns for alternative and multiple futures, it is best left to those familiar with the East to discuss them. But second, and more important for my purposes, are the examples of the West. Commentators have noted (most with disdain) the dominance of Western culture over Eastern culture, and the likelihood of that continuing in the futures(s). (This notion is problematised in [3]). And yet even within this dominant, or to use the more fashionable term, hegemonic, Western worldview, possibilities for multiple futures exist. In his essay 'The Question Concerning Technology', Martin Heidegger makes use of a passage from the poem 'Patmos', by 
Friedrich Hölderlin. Here, Heidegger suggests that within technology (or more accurately, within techné) may lie the way from techne. ${ }^{1}$ This is a provocative image. Within something may lay the way from it. I think that Hölderlin's same simple aphoristic passage may apply to finding paths from the West within the West. (Not to mention that we may have no choice.) Hölderlin writes "Wo aber Gefahr ist, wächst das Rettende auch" [5]. This passage is variously translated. I prefer a mixture of the translations: "But where danger is, grows the salvation also.".

Further still, with the idea of shuttling, we need not even disrupt the cherished Western notion of pasts leading to, or at least pointing toward, futures, in order to find possibilities for alternatives and multiplicity. This is indeed possible when we subject ontic beings to historical placement. Here I am not challenging ideas regarding the representation of material things. I need not go that far. It is in fact in the realm of symbol and meaning that my comments take root. For example, placing the notion of democracy or university into history casts shades of colour unseeable when one's ontological glasses allow one only to see these phenomena in black and white: as always and already having been and continuing to be, and always and already to have been, the same static, abstract thing. This brings us to another example, which is far more important and powerful, and one yet more abstractthe notion of contradiction. And it is here, with the idea of contradiction, that we may well begin to examine the ways in which we move among ideas, in reflecting on the differences of shuttling among ideas or synthesising them. Contradiction provides not only an example of an idea better understood in its historical context, but also an example of an idea which constrains the possibility of multiple beings in the ontological present, in the past, and within our commonly-held belief in history's projection, in the future(s) as well. So how and when did we come to this idea of contradiction in the West?

While searching for a science which investigates being, and the type of person best equipped for practising this science, Aristotle alights on the notions of contrarieties and contradictions. "For all things are either contraries or composed of contraries, and unity and plurality are the starting-points of all contraries." (Metaphysics, Book IV, 2, 1005a). According to Aristotle, the most certain principle of all is,

that the same attribute cannot at the same time belong and not belong to the same subject in the same respect; we must presuppose, in face of dialectical objec-

1 Heidegger refers to this passage of Hölderlin's in his essay 'The Question Concerning Technology'. The editor, David Farrell Krell, refers the reader to 'Patmos', in Hamburger [4, pp. 462-3].

${ }^{2}$ Heidegger's translator, David Farrell Krell, cites the Michael Hamburger translation: "But where danger is, grows the saving power also." But, in Friedrich Hölderlin [5, p. 245], Michael Hamburger translates it as "But where danger threatens, that which saves from it also grows." Translator David Constantine, in Friedrich Hölderlin [6, p. 39], translates it as "Where there is danger some salvation grows too." Translations vary, in large part due to the difficulty with translating the German grammatical substantiation-in this case 'Das Rettende', literally 'the saving' where saving is a substance or a noun. In any case, 'power' is nowhere to be found in the German, and 'salvation' carries a religious tone that 'saving' does not. This may then be more faithful to the circumstances under which Hölderlin wrote this poem for the Landgrave of Homburg - his assignment was to write a work of true Christian piety. 
tions, any further qualifications which might be added.... For it is impossible for any one to believe the same thing to be and not to be,.... (Metaphysics, IV, 3, 1000b).

Here, Aristotle adds the notion of dialectic to the discussion. If we take shuttling seriously, what does it mean for an idea like dialectic? It means that two or more positions are still in discourse-dia-lectic. But it means that insofar as we have a different position after the presentation of a thesis and antithesis, the different position is not a synthesis. This in turn, has grave consequences for notions of progress, as I mentioned above, if one describes progress as the quantitative process of one synthesis after the next.

A focus upon the relationships between futures, rather than just upon the substance of the futures themselves, helps to open up the assumptions we all hold about the relationships among various and multiple futures. A prevalent assumption seems to be that once futures, as represented by parties, are put into discourse, they will influence one another to change their positions, and if the model of dialectic holds good, their ultimate position will be the best because it will have been based upon the examination of all positions by all parties.

Instead I would de-emphasise the idea that simply putting the parties in discourse is going to result in distilling several positions into one. Rather, I would suggest, that we better understand the appropriateness of each position, and recognise that appropriateness can change over time, much in the Greek sense of kairos, rather than chronos. If we eliminate forever, under the banner of progress, several possibilities today, we lose the viability of those possibilities for future(s). Instead, if we proceed with an attitude not to eliminate all but one possibility, or to take bits and pieces of many in a synthesis, but rather to choose appropriately for the time and place, then we may benefit from the possibility of each party understanding the other's position. Each need not try to negotiate ideas away from the other. Better informed parties will then be able to select the appropriate times and places.

In his Metaphysics, Aristotle then makes the bridge between contraries (oppositions in the metaphysical realm of ontic being) to contradictions (spoken oppositions), and here we can begin to see more clearly how this might impact on the symbolic process of future creation-an abstraction only accomplished by words and images:

it is impossible for the same man at the same time to believe the same thing to be and not to be; for if a man were mistaken in this point he would have contrary opinions at the same time. It is for this reason that all who are carrying out a demonstration refer it to this as an ultimate belief; for this is naturally the starting-point even for all the other axioms. (Metaphysics, IV, 3, 1005b).

Apparently uncomfortable to assert his proposition based upon a presupposition only, Aristotle doth protesteth a bit too much when he continues by employing argument ad hominem, "Some indeed demand that even this shall be demonstrated, but this they do through want of education, for not to know of what things one may 
demand demonstration, and of what one may not, argues simply want of education. For it is impossible that there should be demonstration of absolutely everything; there would be an infinite regress, so that there would still be no demonstration." (Metaphysics, IV, 4, 1006a) Having realised the morass of regression that he has put himself in, Aristotle chooses not to go further by trying to justify how he decided, along this point of regression, where to stop. The principle of non-contradiction then remains conveniently, but unfoundedly, the point at which Aristotle chooses to end the regressive process of looking for axiomatic principles. ${ }^{3}$ Together with his prior statement that "all who are carrying out a demonstration refer it to this as an ultimate belief; for this is naturally the starting-point even for all the other axioms" (Metaphysics, IV, 3, 1005b), Aristotle's conclusion that "if there are things of which one should not demand demonstration, these persons cannot say what principle they regard as more indemonstrable than the present one" (Metaphysics, IV, 4, 1006a) places his principle of non-contradiction on a foundation of intersubjective truth, not upon ontic being, nor upon material nature. "Natural science also is a kind of wisdom, but it is not the first kind.-And the attempts of some who discuss the terms on which truth should be accepted, are due to a want of training in logic;....." (Metaphysics, IV, 3, 1005b).

The restriction on multiple meanings, and as a consequence, on multiple futures follows immediately thereafter: "And it makes no difference even if one were to say a word has several meanings, if only they are limited in number; for to each formula there might be assigned a different word.... If, however, they were not limited but were to say that the word has an infinite number of meanings, obviously reasoning would be impossible; for not to have one meaning is to have no meaning,...." (Metaphysics, Book IV, 4, 1006b). This construction again avoids the difficult issue of how the multiple meanings, if they be allowed, are set. How and who and why can some meanings be said to be outside the set of meanings that exist? Is it the possibilities that may not be infinite, or the actualities that may not be infinite?

Lest you think that I am making too much of ancient Aristotle, rightly or wrongly, ${ }^{4}$ I would maintain that western culture does continue to find some of its symbolic roots in Aristotle. This symbol of pedigree may be trotted out dogmatically as a comfortable appeal to history and authority. In addition, sound bites may be taken out of context to lend epigrammatic polish to otherwise thoroughly contemporary texts. A relevant example of this would be none other than a work called The Handbook of Research Synthesis [10], a textbook on the subject of research synthesis in science. This textbook begins with an epigram, listed with no more of a reference than Aristotle's De Anima: “... it is necessary, while formulating the problems of which in our advance we are to find the solutions, to call into council the views of those of our predecessors who have declared an opinion on the subject, in order that we may profit by whatever is sound in their suggestions and avoid their errors." The

\footnotetext{
${ }^{3}$ W.K.C. Guthrie, in The Sophists [8] maintains that the so-called "principle of non-contradiction" is older than Aristotle.

${ }^{4}$ See, for instance, Martin Bernal's critique of contemporary searching for pedigree in ancient western cultures in Black Athena: The Afroasiatic Roots of Classical Civilization [9].
} 
book concludes its introduction by stating that "Research synthesis' or 'research integration' involves the attempt to discover the consistencies and account for the variability in similar-appearing studies. It is one of a broad array of integrative activities that scientists engage in; its intellectual heritage can be traced back at least as far as Aristotle". [10, p. 4] I bring this up only to illustrate that scientists today do indeed believe that the notion of synthesis comes symbolically from Aristotle. The editors of this text add that "The integrative research review can be defined as the conjunction of a particular primary focus and goal: Research syntheses attempt to integrate empirical research for the purpose of creating generalizations. Implicit in this definition is the notion that seeking generalizations also involves seeking the limits and modifiers of generalizations". [10, p. 5] But wait. If we check the source of the epigram back to Aristotle, we find that the ellipsis in the epigram has replaced the words "For the study of the soul" [11]. It is for the study of the soul that Aristotle may be recommending synthesis. Given that we commonly translate the title of the work from the Latin De Anima as 'On the Soul', this comes as no surprise. This point I raise not to suggest any untoward editing, but to illustrate how easy it is to find evidence 'out there' to support our psychological desire for synthesis; for symbols in which we invest the notion of synthesis. The synthesis textbook authors write of 'conjunctions'. Alchemists (no less then chemists or other scientists) interested themselves in conjunctions as well, but the alchemists noted the mysterious spirit of the conjunctions. In alchemy, as Jung will demonstrate, we can therefore more easily understand synthesis as a symbolic desire.

\section{Isocratean shuttling among modes of thought}

Aristotle's principle of non-contradiction did not materialise out of the ether. Some would argue that much of Hellenic philosophy, Aristotle's principle of non-contradiction being just an example, was birthed during an era when the social position of the philosophical enterprise was to attack aggressively the arguments and worldview of the itinerant teachers of the time- the sophists. In the realm of language ('contradiction') we can shuttle from philosophy to rhetoric and take note of a related concept-antithesis - and how it is considered to be a stylistic scheme 5 . It "occurs when both the wording and the sense, or one or other of them, are opposed in a contrast" [13].

Even here, however, at the birth of the principle of non-contradiction, there was another way that did not require synthesising. Caught between the pursuit of truth announced by philosophers, and the practical utility of the rhetorical skills taught by the sophists, Isocrates at times espoused rhetoric and eschewed philosophy. At other times, Isocrates espoused philosophy and eschewed rhetoric. I suggest that this ambiguity was intentional and purposive. His intent was to shuttle from one to the

\footnotetext{
${ }^{5}$ As opposed to stylistic tropes (although related to the topic of dissimilarity and the topic of contraries.) See E.P.J. Corbett [12].
} 
other as was appropriate, and his purpose was to employ and enjoy the advantages of both. While recognising the inconsistencies between rhetoric and philosophy, Isocrates does not arrive at an either-or choice in which one must be elevated above the other. He instead mobilises a 'both-and' approach, founded upon timeliness (kairos) and appropriateness. Isocrates shuttles between philosophy and rhetoric not by synthesising, but by timely and appropriately applying each to respective phenomena.

How does Isocrates know when rhetoric, as a mode of thought and life, is appropriate and when philosophy, as a mode of thought and life, is appropriate? Isocrates saw the practice of the sciences of geometry and astronomy not as philosophy, but rather as "gymnastic of the mind and a preparation for philosophy" [14]. Philosophy then, for Isocrates, meant more than mechanically sound reasoning. Insofar as philosophy was the arena for a person's moral development, Isocrates had something in common with philosophers, for he too claimed that arena [15]. An important distinction between the two types of moral development however, is found not in what each explicitly says about morality, but in the mode in which each says what is said. In Nietzsche's essay, 'History of Greek Eloquence,' he comments that "He [Isocrates] considers speech to be the cause of all higher culture, including morals: for "we consider those to be intelligent and wise who best know how to converse about things" " $[16, \text { pp. 222-3 }]^{6}$. Isocrates, in shuttling between sophistic rhetoric and philosophy suggests a morality of timeliness; that is, one which does not seek universal truths, in method or result. The morality suggested by universal truth-seeking, as in philosophy, is quite different. Thus it is that Isocratean wisdom arises directly out of his ambiguous relationship to the two disciplines of rhetoric and philosophy in his time.

This is quite different than the popular notion that monumental persons in history were great synthesisers, as when Aquinas 'synthesised' Christianity with the thought of Aristotle, and Kepler 'synthesised' the thoughts of Ptolemy with that of Copernicus. Von Weizsäcker has observed that in the natural sciences, synthesis is characterisable as a desire: "Specialized science is powerless to give us a world-view that could sustain us in the confusion of our existence. And so we are longing for synthesis, searching for the point of vantage from which to gain perspective" [17, p. 1].

In synthesising, we act as though we see multiple phenomena, previously thought to be unrelated, in relationship to each other. What is the agenda for such a position? Synthesis is a manifestation of the desire for progress.

\section{Nietzsche's principle of contradiction as a positive force}

Nietzsche develops his own principle of contradiction in repudiation of Aristotle's law of non-contradiction. Nietzsche's principle of contradiction is found in the

\footnotetext{
${ }^{6}$ Nietzsche does not provide a citation from the Isocratean corpus for his quotation. Isocrates' sentiment is alive and well in corporate America today. A colleague of mine attended a business management seminar, and the official word from the pulpit of industry's captains was that when interviewing job candidates, a valid indicator of any job candidate's intelligence is his or her verbal ability to express himself or herself.
} 
posthumously published collection of Nietzsche's notes The Will to Power at fragment number 516."Leaving dialectical opposition behind, Nietzsche finds no particular word or concept 'villainous' or offensive in itself...." [18]. Just as Aristotle found the notion of non-contradiction to be the most fundamental, Nietzsche found that the most fundamental 'value' of all [is] the principle of noncontradiction [19, p. 125]. In section 516 of his The Will to Power, Nietzsche discusses how Aristotle's law of non-contradiction is founded upon a norm of what we should count as being true, not upon what we can know to be true. Nietzsche then goes on to demonstrate the symbolicity that lies at the base of the principle of non-contradiction, and concludes:

The conceptual ban on contradiction proceeds from the belief that we are able to form concepts, that the concept not only designates the essence of a thing but comprehends it-In fact, logic (like geometry and arithmetic) applies only to fictitious entities that we have created. Logic is the attempt to comprehend the actual world by means of a scheme of being posited by ourselves; more correctly, to make it formulatable and calculable for us... [20].

Thus, Nietzsche's "deconstruction of logical and mathematical truth is based on the fact that it is not rooted in knowledge but that it depends on a prior act of assumption" [19, p. 125]. Nietzsche finds that "nothing in the world essentially opposes anything else; everything is of one substance". Nietzsche goes one step further in that he names that one substance "the will to power." For Nietzsche, "opposition is a logician's sham, a linguistic consequence" [21]. "There are no opposites: only from those of logic do we derive the concept of opposites-and falsely transfer it to things""

This provides an additional possibility. Calling all 'the one' recognises that when we devise differences, we do so due to our cognitive limitations to entreat sameness - time, for instance may be one such example - the near and the far is another. Shuttling, as opposed to synthesis, highlights the arbitrary, or at best useful distinctions we erect, noting that they are in no way 'natural.'

How is it that we come to make the logical presupposition of things-in-themselves existing a priori? By the symbolic manipulation of metaphor. Nietzsche views the concepts with which knowledge operates as a three-stage metaphorical translation beginning with a nerve stimulus transferred to an image. The image in turn is imitated in a sound and from this sound (the word) comes the concept. " substitution of knowledge for mere sensation becomes paradigmatic for a wide set of aberrations all linked to the positional power of language in general, and allowing for the radical possibility that all being, as the ground for entities, may be linguistically 'gesetzt,' a correlative of speech acts.... What has and will be shown, within

\footnotetext{
${ }^{7}$ Nietzsche [20, p. 298, fragment 552]. For a further analysis of Nietzsche's view of opposites, see Gayatri Chakravorty Spivak's preface to Jacques Derrida [22, xxviii-xxix].

${ }^{8}$ Friedrich Nietzsche [23, part VI, pp. 21 and 79]. See Schrift [24, p. 375].
} 
the confines of this particular fragment [516], is the possibility of unwarranted substitutions leading to ontological claims based on misinterpreted systems of relationships...." [19, p. 123].

\section{Alchemical symbols and the desire for synthesis}

We may have become so accustomed to treating the natural world as a material world, and the material world as a scientific world, that we have very much lost the ability to talk of any of these worlds in their capacity for symbols. Therefore it may serve as a useful bridge to consider the symbolic nature of the world in a slightly different category from material science-alchemy. The destruction of alternatives begun by the principle of non-contradiction and carried out by the related desire to synthesise continued in alchemy with the destruction of its symbolic nature. Typically, alchemy is known only for its material practice of trying to produce gold; a process which would fit within the definition of synthesis. I think this is illustrative of all attempts at syntheses-they are attempts to produce an artificial gold, material or symbolic. Carl Jung has suggested that more important for alchemy than the material production of gold was the symbolic production of meaning. As Jung points out, "It was not the common gold that enters into combination but the spirit of the gold...." [25, p. 517].

In working the bridge between the material and the symbolic, Jung notes that the alchemist used fantasy images "more as technical terms for expressing the mysterious properties which he attributed to his chemical substances. The psychologist, on the contrary, regards them not as allegories but as genuine symbols pointing to psychic contents that are not known but are merely suspected in the background, to the impulses and 'idée forces' of the unconscious.... The images often show such a striking resemblance to mythological motifs that one cannot help regarding the causes of the individual fantasies as identical with those that determined the collective and mythological images. In other words, there is no ground for the assumption that human beings in other epochs produced fantasies for quite different reasons, or that their fantasy images sprang from quite different idées forces, from ours.... But if we treat their symbols in the same way as we treat modern fantasies, they yield a meaning such as we have already deduced from the problematical modern material" [25, pp. 518-9].

"The illusions would not be so common if they did not serve some purpose and occasionally cover up a painful spot with a wholesome darkness which one hopes will never be illuminated" [25, p. 520]. "What the alchemist sought, then, to help him out of his dilemma [of finding a procedure for 'fixing' the substance of the soul] was a chemical operation which we today would describe as a symbol" [25, p. 526]. Jung asks, "what is the psychological meaning of the [alchemical] procedure?" [25, p. 487]. He observes that this drive to create meaning through symbols is a manifestation of a psychological need. [Coincidentally, this creation of meaning for Jung's 
psychotherapy has echoes in Victor E. Frankl's logotherapy, which would come later (see [26]). More importantly, he observes that the process of symbol creation is a process of conjunction. And the coniunctio, according to Jung, is the central idea of the alchemical procedure. Moreover, Jung held that "alchemy was, in the main, symbolical...." [25, p. 457]. So here we one can observe that in the natural sciences and philosophy, the notion of synthesis may also be seen in the light of a desire for symbol creation, emanating not from the material properties of nature, but from the psychological properties of human desire.

In shuttling from the micro world of the individual, to the collective world of whole cultures, we come to a point that is perhaps illustrative of part of Martin Bernal's Black Athena thesis. According to Jung, "the relation of alchemical fantasies to the primordial images of Greek mythology is too well known for me to document it. [Presumably, he means it is too well known to need documentation.]... The cosmogenic brother-sister incest, like the Creation itself, had been from ancient times the prototype of the alchemists' great work. Yet we seek the Graeco-Roman tradition in vain for traces of the wonder-working monoculus" [25, p. 516].

\section{What is more splendid than light?}

Jung's inspiration for his extended look at the mysterious conjunctions in the symbols of alchemy was inspired in part by Goethe's Faust. Ironically, according to Victor Lange, editor of one edition of Goethe's Faust, "In 1800 Goethe read a significant section... to his friend Schiller who called it a 'synthesis of the noble and the barbarous"" [27, p. viii].

It is significant that Goethe, the author of Faust, considered himself to be a better scientist than author or poet. In that vein, his most extensive undertaking was a work in phenomenological science, Theory of Colours. The need to account for the human experience of colour, rather than just the wavelengths of light, drove Goethe to include in Theory of Colours a long polemical part written against Isaac Newton's work Optiks. (It bears mentioning that Newton himself practised alchemy.) Additionally, Goethe does point to what about alchemy is for him important when his character asks: "What is more splendid than gold? Light. What is more refreshing than light?-Conversation" [28, p. 374].

The refreshing practice of conversation and the symbolic nature of chemistry are explored by Goethe in his novel, Elective Affinities. Contrary to the trend to reduce human behaviour to material behaviour, in Elective Affinities, Goethe instead explores the natural world - specifically chemistry-by human relationships.

Elective Affinities is not simply a convenient parable for Goethe. It is a powerful example of the way in which symbols form our understanding of not only things symbolic, but of things natural as well. One finds in chapter IV of Elective Affinities, a renaissance man of the world known throughout the novel only as 'the Captain' explaining 'affinities', as a term in chemistry, to his best friend's wife, Charlotte. It is no coincidence that the Captain and his friend's wife have certain affinities toward each other as well. Regarding 'affinities', Charlotte states "I only want to know the 
meaning of the word.... What its scientific application is I am quite contented to leave to the learned; who, by-the-by, as far as I have been able to observe, do not find it easy to agree among themselves." The explanation of the symbol which the Captain and Charlotte's husband, Edward, provide in response to her demand quickly moves to one of the relationship of parts to a whole.

"I think," interrupts Edward, "we can make the thing more clear to her, and to ourselves, with examples; conceive water, or oil, or quicksilver; among these you will see a certain oneness, a certain connection of their parts; and this oneness is never lost, except through force or some other determining cause. Let the cause cease to operate, and at once the parts unite again." Here we see Goethe's notion that a certain wholeness or oneness is a natural state, unless interrupted by separating causes. This natural state of wholeness is clearly distinguishable from a synthesised state of combination. In the event the reader has not noticed that as Edward and the Captain explains the natural world as symbols to Charlotte, Goethe explains his own position that we understand the natural world as symbols. He puts his position in the mouths of Charlotte and Edward: "One can almost fancy that in these simple forms one sees people that one is acquainted with; one has met with just such things in the societies amongst which one has lived; and the strangest likenesses of all with these soulless creatures are in the masses in which men stand divided one against the other, in their classes and professions; the nobility and the third estate, for instance, or soldiers and civilians." Edward makes yet plainer and simpler the formula that we understand the relationships of the natural world because of our own symbol relationships, each with the other. Says Edward: "Then again, as these are united under common laws and customs, so there are intermediate members in our chemical world which will combine elements that are mutually repulsive." "Most certainly," answered Edward; "the title with which chemists were supposed to be most honorably distinguished was, artists of separation."

Charlotte then makes an impassioned argument for the artistry of union, not separation, and Edward and the Captain respond by agreeing with Charlotte that nature can be either, since we know it through symbols. In the end, the discussion of chemical affinities is a discussion about human beings, very obviously. Yet a more subtle position that Goethe may be advocating is that any discussion of nature is a discussion about human nature, insofar as we know nature through human understanding; in short, through symbols. Says Charlotte: "But man is raised very many steps above these elements; and if he has been somewhat liberal with such fine words as Election and Elective Affinities, he will do well to turn back again into himself, and take the opportunity of considering carefully the value and meaning of such expressions." After this the Captain notes: "In this forsaking and embracing, this seeking and flying, we believe that we are indeed observing the effects of some higher determination; we attribute a sort of will and choice to such creatures, and feel really justified in using technical words, and speaking of "Elective Affinities", [29, pp. 31-7]. 


\section{7. 'I await myself in the future'}

I have made my point elsewhere [30, pp. 19-35] that it is language which supplies us with the necessary ability of abstraction necessary to create the abstractions known as 'past,' 'present', and 'future'. Sartre provides us with a particularly good example of the consequences of our tacit belief in Aristotle's principle of non-contradiction as it relates to the linguistic creation of the future. I have organised my reading of that example under the banner of his phrase "I await myself in the future" [31, p. 73].

Writing in a style to describe the is-ness of the world-that is to say, in ontological terms-Sartre commented that: "Popular consciousness has so much trouble in refusing a real existence to the past that alongside the thesis just discussed ['The past, it is said, is no longer.'] admits another conception equally imprecise, according to which the past would have a kind of honorary existence" [31, p. 160]. According to Sartre, Husserl and Bergson would claim that the past is. Sartre seems to want to emphasise that it is due to imprecision that these two theses could exist alongside each other. Consequently, he is suggesting that it should not only make these theses more precise, then...; then what? Apparently, with precision would come the clarity of contradiction. And with contradiction would come the elimination of one in favour of the other. "There is not first a universal past which would later be particularised in concrete pasts. On the contrary, it is particular pasts which we discover first.... The true problem-which we shall attack in the following chapter-will be to find out by what process these individual pasts can be united so as to form the past" [31, p. 165]. But this process is not a one-way street. Given that Sartre was a phenomenologist, one would hope that he would have seen this-we are thrown into a world already with a universal sense of the past from which we make sense of particulars. Sartre here has answered his own query-particular pasts are understood in terms of the whole first, then particularised.

Sartre goes on to say that "Temporality is evidently an organized structure. The three so-called 'elements' of time, past, present, and future, should not be considered as a collection of 'givens' for us to sum up-for example as an infinite series of 'nows' in which some are not yet and others are no longer-but rather as the structured moments of an original synthesis" [31, p. 159].

Otherwise, according to Sartre, we will meet with a paradox in which the past is no longer and the future is not yet, and since the present is only the demarcation of past from future with no independent existence of its own, we are left with a nihilistic sense of time. He finds the power to create temporality in language - the term 'was'. "The term 'was' indicates the ontological leap from the present into the past and represents an original synthesis of those two temporal modes. What must we understand by this synthesis?" [31, p. 168].

\section{Conclusions}

Just as Hume demonstrated with the notion of inductive causation, it is we who supply the abstract notion of synthesis to other abstractions which we have created. 
This process of creating syntheses is a manifestation of a symbolic desire. Jung notes that symbolic desires can come about in ways that suggest that they are common to more than one culture. Synthesis does this. Its pervasiveness in no way attaches it to some sort of natural or material category. This fact is perhaps best demonstrated within the material realm of scientific chemistry itself, and the way in which it speaks of synthesis as being an artificial joining. The implications for future studies are important insofar as they suggest that we focus not just upon those abstract moments in time and space that we will concretise as being separately identifiable futures, but also upon the relations between the concretised abstract moments-relations better practised and understood as shuttling, not synthesis, if we want to preserve the possibilities of multiple futures.

\section{References}

[1] Daintith J, editor. A concise dictionary of chemistry. Oxford: Oxford University Press, 1985.

[2] Bronowski J. The ascent of man. London: Little, Brown and Company, 1976.

[3] Goody J. The East in the West. Cambridge: Cambridge University Press, 1999.

[4] Hölderlin F. Poems and fragments. Ann Arbor: The University of Michigan Press, 1966. Hamburger M, Trans.

[5] Hölderlin F. In: Santner EL, editor. Hyperion and selected poems. New York: Continuum, 1990:245.

[6] Hölderlin F. Selected poems. Newcastle upon Tyne, UK: Bloodaxe Books, 1990. Constantine D, Trans.

[7] Aristotle. Metaphysics.

[8] Guthrie WKC. The sophists. Cambridge: Cambridge University Press, 1971.

[9] Bernal M. Black Athena: the Afroasiatic roots of classical civilization. London: Free Association Books, 1987.

[10] Cooper H, Hedges LV, editors. The handbook of research synthesis. New York: Russell Sage Foundation, 1994.

[11] Aristotle. On the Soul, Book I.1. In: Barnes J, editor. The complete works of Aristotle. Princeton: Princeton University Press, 1984:403b.

[12] Corbett EPJ. Classical rhetoric for the modern student. 2nd ed. New York: Oxford University Press, 1971.

[13] Rhetorica ad Alexandrum, Chapter 26, [Forster ES, Trans.], as quoted in Corbett EPJ. Classical rhetoric for the modern student, 2nd ed. New York: Oxford University Press, 1971:465.

[14] Isocrates. Three volumes 'Antidosis' [Norlin G, Van Hook L, Trans.]. Cambridge, MA: Harvard University Press 266, 1980.

[15] Poulakos J. Sophistical rhetoric in classical Greece. South Carolina: University of South Carolina Press, 1995.

[16] Nietzche F.On rhetoric and language New York: Oxford University Press, 1989. Gilman SL, Blair C, Parent DJ, editors and translators.

[17] Von Weizsäcker CF. The history of nature Chicago: University of Chicago Press, 1949. Wieck D, Trans.

[18] Desilet G. Nietzsche contra Burke: the melodrama in dramatism. Quarterly Journal of Speech, 75.

[19] De Man P. Allegories of reading. New Haven: Yale University Press, 1974.

[20] Nietzsche. The will to power, 279-80. Walter Kaufmann and RJ Hollingdale, trans.: New York: Random House, 1967.

[21] Desilet G. Nietzsche contra Burke: the melodrama in dramatism, 74, citing Kaufmann W. Nietzsche. New York: Vintage Books, 1968:235.

[22] Derrida J. Of grammatology, 1st American ed. Baltimore: John Hopkins University Press, 1976. Spivak GC, Trans. 
[23] Nietzsche F. Human, all-too-human: a book for free spirits. Lincoln: University of Nebraska Press, 1984. Faber M, Trans.

[24] Schrift, Alan D. Nietzche and the Question of Interpretation. New York: Routledge, 1990, 375.

[25] Jung CG. Mysterium coniunctionis: an inquiry into the separation and synthesis of psychic opposites in alchemy, 2nd ed. London: Routledge and Kegan Paul, 1970. Hull RFC, Trans.

[26] Frankl VE. Man's search for meaning: an introduction to logotherapy (revised and enlarged). London: Hodder and Stoughton, 1987.

[27] Goethe JW. Faust. New York: Continuum, 1994.

[28] Goethe JW. 'Das Märchen', Werke, Artemis edition, 1795.

[29] Goethe JW. Elective affinities. New York: Frederick Ungar Publishing Co Inc, 1962. Froude JA, Boylan RD, Trans., original work published 1807.

[30] Junker KW. How the future is cloned. In: Sardar Z, editor. Rescuing all our futures. London: Adamantine Press, 1999.

[31] Satre J-P. Being and nothingness: a phenomenological essay on ontology. London: Washington Square Press, 1956, Barnes HE, Trans. 